scientił studia, São Paulo, v. 3, n. 3, p. 395-414, 2005

\title{
ist \\ Galileu contra a inércia circular
}

\author{
Júlio Celso Ribeiro de Vascongelos
}

$\ddot{\circ}$

RESUMO

Segundo os estudiosos que propõem a "inércia circular" como um dos principais aspectos do sistema conceitual de Galileu, o italiano pioneiro da física moderna acreditava que somente movimentos circulares em torno do centro de um corpo cósmico, como a Terra, poderiam persistir sem a ação de uma força. Essa interpretação amplamente aceita está baseada em excertos das duas principais obras de Galileu, o Diálogo de 1632 e o Discorsi de 1638. Esses estudiosos, entretanto, não levam em consideração certas passagens dessas obras nas quais as palavras de Galileu não estão adequadas a sua interpretação. Discutirei tais passagens de modo a rejeitar a interpretação da inércia circular e para defender o ponto de vista de que o conceito de inércia de Galileu não leva em consideração a trajetória do movimento, mas trata unicamente do "grau de velocidade indelevelmente impresso" em um corpo movente.

Palavras-chave • Inércia. Inércia circular. Conservação de movimento. Mecânica. Galileu.

\section{INTRODUÇÃO}

Galileu é considerado unanimemente um precursor da lei da inércia, mas há muita polêmica sobre a extensão de sua contribuição para o estabelecimento dessa lei. E esse é um debate de fundamental importância, conforme nos explica Dijksterhuis:

[...] a questão de se a compreensão de Galileu da inércia era completa ou se ele somente preparou o caminho em tal extensão que seus sucessores tiveram pouca dificuldade em alcançá-lo pode parecer um ponto de controvérsia entre especialistas ao invés de um assunto que pode ser de interesse para o desenvolvimento principal da história da ciência. Mas nenhuma dessas considerações é válida. De fato, a mudança na concepção de inércia - em conjunto com o novo modo de considerar o efeito de uma força constante agindo sobre uma partícula de matéria - provavelmente constitui o mais importante elemento na transição da ciência antiga e medieval para a ciência clássica [...]. Além do mais, a lei da inércia não é só um detalhe do novo quadro do mundo, mas um dos fundamentos que suportam as partes mais essenciais do sistema (Dijksterhuis, 1986, p. 347-8). 
Assim, dado que a inércia é um dos pilares da chamada física clássica, não é de interesse exclusivo de especialistas a questão da contribuição de Galileu para a sua constituição. Certamente aqui está a primeira das razões para a enorme popularidade da interpretação da inércia circular, que será descrita a seguir e que é o alvo do presente artigo. A outra razão da grande aceitação dessa interpretação é a sua plausibilidade e a força da argumentação de seus defensores, largamente apoiada em pronunciamentos do próprio Galileu.

Não se pretende aqui analisar exaustivamente essa argumentação e os pronunciamentos em que se apóia; o objetivo do presente artigo é trazer à baila outros trechos de punho de Galileu - que os defensores da inércia circular não citam - e mostrá-los inconciliáveis com esse tipo de interpretação. Esses trechos - aliás, como também a quase totalidade dos brandidos em nome da circularidade da inércia - vêm do Diálogo de 1632 e dos Discorsi de 1638, as duas mais importantes obras de Galileu.

É claro que uma guerra completa a tal interpretação não pode prescindir da batalha de desmonte dos argumentos de seus adeptos, o que será objeto de artigo posterior. ${ }^{\mathbf{1}}$ Espera-se, porém, que ao final da leitura do presente artigo fique já evidente que se deve buscar um outro entendimento unificador dos pronunciamentos galileanos concernentes à conservação de movimento. Pretende-se ainda, também ao final do artigo, sugerir um sólido candidato para esse entendimento unificador da conceituação galileana de inércia.

\section{0 “princípio de INÉrGia GIRGULAR” E DUAS DE SUAS FormUlações}

São muitos os que defendem a posição interpretativa que sustenta existir em Galileu um "princípio de inércia circular", mas Paul Feyerabend e Eduard Dijksterhuis são os que efetuam as mais explícitas tentativas de enunciar. Comecemos por ver como Feyerabend nos apresenta o "princípio" em seu Contra o método, na análise que faz da resposta de Galileu ao argumento da torre (como se sabe, este argumento pretendia mostrar serem incompatíveis a hipótese copernicana da rotação terrestre e a queda vertical de uma pedra do alto de uma torre):

Meu exame do argumento anticopernicano não está ainda encerrado. Até agora, tentei descobrir o pressuposto por força do qual uma pedra que se move ao longo de uma torre móvel parece cair "verticalmente", sem que a vejamos tombar segundo

1 O leitor impaciente já poderá ler, em uma e outra das notas seguintes, algumas objeções aos argumentos dos adeptos da inércia circular. 
um arco. Vimos que o artifício é realizado por um pressuposto - que denominarei princípio da relatividade - de acordo com o qual nossos sentidos só notam o movimento relativo, permanecendo inteiramente insensíveis a movimentos que os objetos tenham em comum. Resta explicar, entretanto, por que a pedra acompanha a torre e não fica para trás [...]. O problema é, agora, o de suplementar o princípio de relatividade com uma nova lei de inércia, de maneira tal que se possa continuar afirmando a existência do movimento da Terra. Percebe-se, desde logo, que a lei seguinte, o princípio da inércia circular (tal como o denominarei) propicia a necessária solução: um objeto que se move com determinada velocidade angular em uma esfera livre de atrito, a redor da Terra, continuará a mover-se com a mesma velocidade angular, para todo o sempre. Combinando a visão oferecida pela pedra que tomba com o princípio da relatividade, o princípio da inércia circular e outros pressupostos simples, concernentes à composição de velocidades, chegamos a um argumento que não mais coloca em perigo a concepção de Copérnico e pode ser usado para proporcionar-lhe apoio parcial (Feyerabend, 1977, p. 13o-1; grifos meus).

Uma primeira crítica a Feyerabend diz respeito ao próprio nome que ele atribui ao princípio, que deveria ser "inércia circular geocêntrica", já que não se aplica a todo e qualquer movimento circular, ${ }^{2}$ pois o princípio parece aplicar-se quando o círculo em que se move o objeto tem a Terra como centro.

A segunda crítica tem como alvo o enunciado que Feyrabend propõe para o princípio, sublinhado na citação acima. Este enunciado é obviamente insatisfatório, pois seria melhor substituir o irrealista "continuará a mover-se" pela fórmula "tende a continuar se movendo".

É oportuno também ressaltar que Feyerabend não traz à baila citações de Galileu que possam dar elementos que sustentem a proposta de existência de um tal princípio em sua obra, e menos ainda usa argumentos, seja de que tipo forem, para convencer um eventual leitor renitente; não é esse o objetivo de seu incendiário Contra o método. Aliás, é de se estranhar que muitos acadêmicos considerem Feyerabend um dos principais elaboradores da interpretação da inércia circular e tenham esse livro como principal referência.

O fato é que para conhecermos os argumentos a favor da pertinência da interpretação da inércia circular devemos passar a algum livro de outro de seus defensores, e ninguém mais respeitável que Dijksterhuis, e nenhum livro mais honesto que seu

2. Se o princípio valesse para qualquer círculo, isso caracterizaria uma inércia circular mais geral, em que, por exemplo, uma pedra amarrada a um barbante manteria seu movimento circular depois de solto o barbante, conservação impensável para Galileu e até para o anarquista Feyerabend. 
The mechanization of the world picture podem ser escolhidos. A idéia da inércia circular já aparecia lá explicitamente enunciada - embora não nomeada - anos antes de Contra o método, nos seguintes termos:

A situação é [...] como se segue: de acordo com a lei propriamente galileana de inércia, uma partícula que é livre de influências externas (note-se que a gravidade não está entre elas) persevera em um movimento circular tendo o centro da Terra como seu centro. Para pequenas distâncias, o movimento é considerado retilíneo; subseqüentemente, a limitação a pequenas distâncias é esquecida (pelos sucessores de Galileu), e se diz que a partícula continuaria seu movimento retilíneo indefinidamente num plano horizontal se nenhum fator externo interferisse. Assim, o que poderia ser chamado a visão circular de inércia de Galileu gradualmente se desenvolveu até a concepção que foi formulada na primeira lei de Newton (Dijksterhuis, 1986, p. 352; grifo meu).

Em apoio a essas afirmações, Dijksterhuis cita passagens da primeira jornada do Diálogo em que Galileu diz "admitir que o mundo é um corpo dotado de todas as dimensões e, por isso mesmo, perfeitíssimo" e que "estabelecido, portanto, este princípio, pode-se imediatamente concluir que, se os corpos integrais do mundo devem ser por sua natureza móveis, é impossível que seus movimentos sejam retilíneos, ou diferentes dos circulares" (EN, 7, p. 43; Galilei, 2001, p. 99).

Isso, diz Dijksterhuis, "de modo algum se aplica somente aos corpos celestiais". 3 Justifica essa afirmação descrevendo a discussão, na segunda jornada do Diálogo, "sobre o comportamento de uma bola perfeitamente dura e lisa, que é colocada sobre um plano perfeitamente duro e liso", discussão que conclui que a velocidade de um corpo tende a permanecer constante em um plano horizontal. "Tal plano é uma superfície esférica tendo o centro da Terra como seu centro" (Dijksterhuis, 1986, p. 349-5o).

Assim, segundo Dijksterhuis, o verdadeiro movimento inercial galileano é o movimento num círculo que tem como centro um "corpo integral do mundo" - para usar a conceituação de Galileu - como o Sol ou a Terra; no caso desta última, embora os sucessores de Galileu tenham lido "plano horizontal" na acepção habitual, a consideração atenta das falas do Diálogo, entende Dijksterhuis, mostraria que a contraposição a planos que se aproximam ou se afastam do centro da Terra só pode ser feita por referência à superfície esférica, sempre eqüidistante do mesmo centro.

3 Em um próximo artigo, pretendo mostrar que essa extrapolação de Dijksterhuis é ilegítima e se deve a uma leitura equivocada da original filiação de Galileu ao chamado "axioma platônico", axioma que preconizava para os corpos celestes movimentos circulares e uniformes. 
Como se pode antecipar por essas breves referências ao trabalho de Dijksterhuis, a interpretação da inércia circular é, como já se admitiu, fundada em importantes pronunciamentos de Galileu. No entanto, como veremos a seguir, revela-se incompatível com outros trechos igualmente incontornáveis dos Discorsi e do Diálogo - que os defensores dessa posição, repita-se, não citam - e deve então, como já dissemos, ceder lugar a um novo entendimento de todos os pronunciamentos galileanos concernentes à conservação do movimento.

\section{O movimento inergial asgendente nos Discorsi}

Comecemos pelos Discorsi, mais exatamente pelo escólio da vigésima-terceira proposição da Terceira Jornada (proposição que se abreviará III-23). É nessa jornada que se encontra a teoria galileana dos movimentos naturalmente acelerados. No escólio de III-23, Galileu traz à luz a formulação físico-matemática conhecida como "regra-dadistância-dupla", regra que, em outros trabalhos (cf. Vasconcelos, 1993; 2001), mostrei poder ser entendida como constituindo nos Discorsi um "teorema da inércia".4

Galileu não apresenta para essa regularidade inercial um enunciado formal: entretanto, ele poderia ter a seguinte formulação:

Um móvel que cai a partir do repouso uma certa distância vertical ou inclinada, se desviado horizontalmente após aquela queda, percorre em movimento uniforme, num tempo igual àquele em que caiu, uma distância que é o dobro da distância percorrida na queda.

O teorema da inércia é demonstrado duas vezes no que se pode chamar a primeira parte do escólio de ıı-23; na segunda parte, o teorema é usado no tratamento de um movimento por um plano inclinado ascendente, tratamento em que se revela o uso inequívoco de uma conceituação de conservação de movimento retilíneo não-horizontal.

Essa conceituação, que Galileu apresenta no escólio de III-23 para uma ascensão por um plano inclinado, é a de uma composição de dois movimentos, conforme ilustra a figura 1: (a) um movimento uniforme plano acima, que tende a persistir eternamente

4 A expressão “teorema da inércia” é minha. Também mostrei que esse "teorema da inércia” cumpre no desenvolvimento subseqüente dos Discorsi um papel de insuperável utilidade, na medida em que permite a Galileu prescindir de um princípio de inércia para sua teoria dos projéteis. Aliás, por essa e outras razões, creio que a interpretação da inércia circular não resiste a uma análise físico-matemática detida das proposições da ciência do movimento que Galileu apresenta na Terceira e na Quarta Jornada dos Discorsi. 
no corpo; (b) outro movimento acelerado plano abaixo, causado pela gravidade. Deixemos que o próprio Galileu nos explique o que tem em mente. (A figura e o grifo na citação são meus, como é minha a sugestão de comparar a conceituação de Galileu com o nosso habitual $v=v o-\gamma \cdot t)$ :

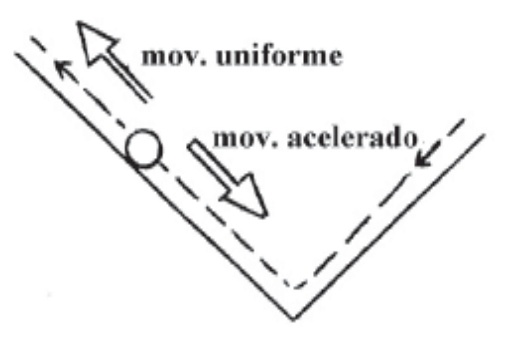

[...] se um móvel adquire por um movimento natural de descida um certo grau de velocidade, que é por natureza indelével e eterno, devemos considerar que se, após a descida por um plano inclinado descendente, o movimento se desvia por outro plano inclinado ascendente, então acontece neste plano uma causa de retardamento, visto que sobre tal plano o mesmo móvel desce naturalmente; razão pela qual resulta uma mistura de propriedades opostas, ou seja, de um lado, o grau de velocidade adquirido durante a descida precedente, que por si mesma faria com que o móvel se movesse infinitamente com velocidade uniforme e, de outro lado, a tendência natural do movimento para baixo com sua proporção constante de aceleração. Se investigamos, portanto, o que acontece quando um móvel, após ter descido por um plano inclinado qualquer, passa a subir por outro plano, parece razoável admitir que o grau máximo de velocidade adquirido durante a descida se conserva perpetuamente idêntico no plano ascendente; contudo, na subida lhe sobrevém uma inclinação natural para baixo, ou seja, um movimento acelerado que, partindo do repouso, segue na proporção habitual (EN, 8, p. 243; Galilei, 1988, p. 213-4).

A seguir, ainda no escólio de III-23, Galileu estende para o plano inclinado ascendente a propriedade matemática do "teorema da inércia", que já sabemos ter sido demonstrada para planos horizontais, na primeira parte do escólio. Essa extensão está no trecho abaixo reproduzido (mais exatamente na passagem grifada); o que Galileu consegue com ela é dar uma explicação inequivocamente físico-matemática para o fato de que a bola em ascensão atinge - se não houver evidente dissipação - a mesma altura de onde ela foi abandonada.

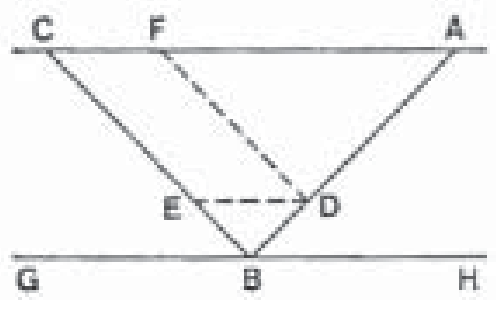

Com o intuito de dissipar os possíveis pontos obscuros deste raciocínio, recorramos a uma figura para uma explicação mais clara. Imaginemos, portanto, que o movimento acontece sobre um plano descendente $A B$ e que, após ter sido desviado, continua imediatamente pelo plano ascendente $B C[\ldots]$ no plano 
horizontal $G H$, o movimento continuaria uniforme ao infinito com o grau de velocidade adquirido em $B$, após a descida por $A$. Por sua parte, essa velocidade seria tal que, num tempo igual ao tempo de descida por $A B$, o móvel percorreria sobre a horizontal $G H$ uma distância que é o dobro de $A B$. Imaginemos agora que $o$ mesmo móvel com o mesmo grau de velocidade se movimente uniformemente sobre o plano $B C$, de tal forma que ainda sobre este ele percorre num tempo igual ao tempo de descida por $A B$ uma distância que seria o dobro da própria distância $A B$. Devemos entender, contudo, que apenas começa a subir, acontece-lhe por sua própria natureza o mesmo que lhe acontecia quando se movimentava a partir de $A$ sobre o plano $A B$, ou seja, um movimento acelerado a partir do repouso, com o qual, sendo a aceleração a mesma, ele desceria pelo plano ascendente no mesmo tempo uma distância igual àquela que desce por $A B$. É evidente que, devido a essa mistura de um movimento uniforme ascendente e de um movimento acelerado descendente, o móvel será levado sobre o plano $B C$ até o extremo $C$ com os mesmos graus de velocidade que serão iguais (EN, 8, p. 244; Galilei, 1988, p. 214; grifos meus).

Nesse trecho dos Discorsi, Galileu faz interagirem a composição que herdou de Arquimedes - aplicada aqui a movimentos de sentidos contrários - e o teorema da inércia, estendido para o plano inclinado ascendente, para obter a simetria entre o movimento acelerado por um plano descendente e o movimento retardado por outro plano, ascendente, de inclinação igual à do primeiro. Mas o que merece mais destaque, para nossos fins, é que vimos o movimento ascendente ser "imaginado" em princípio perdurar, o que está em total desacordo com o entendimento dos defensores da inércia circular de que, para Galileu, só o movimento horizontal pode ser considerado um movimento inercial. Talvez por isso, a segunda parte do escólio de III-233 raramente é citada por eles; na verdade, parece que o único que a cita é Dijksterhuis, mas revelando total desatenção para com sua estrutura e desenvolvimento:

O Galileu-mito, seguindo E. Mach nisso, insiste em afirmar que Galileu imaginou o plano $B C$ girar em torno de $B$ e o fez aproximar-se do plano horizontal $B G$. A partícula então invariavelmente tem que se mover até alcançar de novo o nível de $A$ e, uma vez que sobre o plano horizontal isso nunca acontecerá, ela continuará a mover-se uniformemente sobre o plano com a velocidade adquirida durante sua descida de $A$ para $B$. Desse modo, alega-se que Galileu derivou a lei de inércia. O texto desse trabalho, entretanto, não mostra nenhum traço desse raciocínio e o leitor verá aqui que Galileu nunca poderia ter raciocinado desse modo (Dijksterhuis, 1986, p. 347). 
O desejo de fortalecer suas teses é tão intenso que Dijksterhuis, embora tenha razão em atentar para a falsidade do raciocínio descrito no "Galileu-mito", parece não ter lido os trechos acima do escólio de III-23, onde Galileu, como vimos, declara com todas as letras não só que "no plano horizontal $\mathrm{GH}$, o movimento continuaria uniforme ao infinito com o grau de velocidade adquirido em $B$, após a descida por $A$ " (os raciocínios que justificam isso estão, como já se disse, na primeira parte do escólio), como também que "o grau máximo de velocidade adquirido durante a descida se conserva perpetuamente idêntico no plano ascendente". Vale a pena insistir (já que a interpretação da inércia circular parece ter incomparável poder de encantamento) que Galileu não só visualiza a conservação de um movimento uniforme horizontal em linha reta (sem girar plano nenhum), como também vê um movimento retilíneo inercial 5 ascendente como componente do movimento retilíneo ascendente.

\section{A PRESERVAÇÃo Do MOVIMENTO RETILÍNEO NA EXTRUSÃo}

Há no Diálogo dois outros momentos notáveis de afirmação de conservação de movimentos retilíneos. Essas passagens - também compreensivelmente negligenciadas pelos adeptos da inércia circular - ocorrem quando os personagens Salviati, Sagredo e Simplício discutem o argumento anticopernicano da extrusão, segundo o qual, caso a Terra girasse, isso resultaria "na demolição de construções, e na projeção das pedras, dos animais e dos próprios homens para o céu" (EN, 7, p. 215; Galilei, 2001, p. 270).

Como as armas que Galileu brandirá contra o argumento da extrusão têm sofisticado caráter matemático, é Salviati, o porta-voz de Galileu, que toma a iniciativa nesse combate. Não podemos aqui acompanhar a seqüência de ataques de Salviati, por isso passemos aos momentos que mais diretamente nos interessam. $O$ primeiro deles se situa na discussão da experiência comum de se observar "os meninos lançarem as pedras a grande distância com o giro de um pedaço de cana, na ponta do qual foi encaixada a pedra" (EN, 7, p. 216; Galilei, 2001, p. 271). No meio da longa discussão, Salviati assim sumaria o que estabeleceu até então com o aristotélico Simplício:

[...] Até aqui soubestes por vós mesmos que o movimento circular do arremessador imprime no projétil o ímpeto de mover-se (quando acontece que eles se separam) pela reta tangente do círculo do movimento no ponto de separação, e continuando o movimento por essa tangente, afasta-se sempre do arremes-

5 É preciso confessar que a expressão "movimento inercial" está sendo usada sem rigor e sua adequação às conceituações de Galileu poderia ser facilmente contestada. Peço ao generoso leitor, porém, que tolere a licença terminológica. 
sador; e dissestes que por tal linha reta o projétil continuaria a mover-se, quando não lhe fosse acrescentada pelo próprio peso uma inclinação para baixo, da qual deriva a encurvação da linha do movimento. Parece-me também que soubestes por vós mesmos que esse encurvamento tende sempre para o centro da Terra, porque para lá tendem todos os graves (EN, 7, p. 220; Galilei, 2001, p. 275; grifo meu).

As palavras acima sugerem fortemente uma aproximação com as conceituações inerciais newtonianas. Mas não é necessário - e nem correto - ir tão longe. Basta ressaltar que elas trazem uma inequívoca afirmação da tendência de conservação do movimento retilíneo inicial de um projétil. E registrar que não teria sustentação aqui um argumento típico dos adeptos da inércia circular, o de que os movimentos retilíneos, que Galileu imagina poderem ser conservados, são sempre horizontais, movimentos que na verdade seriam pequenos trechos de movimentos circulares aproximados para retilíneos. Não é isso que se tem aqui, o que é evidenciado pelo trecho acima e por uma leitura detida - que infelizmente foge das possibilidades deste trabalho - da longa discussão sobre o projétil lançado por um pedaço de cana.

O segundo momento que nos interessa destacar, um pouco mais adiante do que acabamos de ver, se dá quando já se discute explicitamente a plausibilidade da extrusão devida à rotação terrestre. Salviati caracteriza assim a linha pela qual se daria a "projeção", isto é, a alegada expulsão dos corpos terrestres no argumento da extrusão.



Tracemos [...] uma linha perpendicular para o centro [da Terra], e seja esta $A C$ e, formando ângulos retos com ela, seja a horizontal $A B$, sobre a qual se faria o movimento da projeção e pela qual continuaria o projétil com um movimento uniforme (con movimento equabile), quando a gravidade não o inclinasse para baixo (EN, 7, p. 225; Galilei, 2001, p. 280; grifos meus).

Note-se que a horizontal aqui é uma linha reta que se afasta do centro da Terra e não pode, de modo algum, ser entendida circular como fazem os que crêem na inércia circular nos trechos que gostam de citar. Mais ainda, Salviati diz explicitamente que sobre essa linha essencialmente retilinea e ascendente o movimento permaneceria uniforme, o que também é muito difícil de se conjugar com o ponto de vista de que a inércia circular descreve completa e perfeitamente as concepções galileanas de movimento inercial. 


\section{Velocidades angular E LiNear:}

\section{UMA IMPOSSIBILIDADE DE GONSERVAÇÃO SIMULTÂNEA}

Até aqui, investimos contra a inércia circular trazendo à atenção do leitor trechos em que se afirma a tendência de conservação de movimentos retilíneos não assimiláveis a movimentos circulares. Agora passaremos a outro confronto com a inércia circular, remetendo desta vez a uma dificuldade interna dessa interpretação, ao que parece, nunca reconhecida por seus defensores. É que, considerada rigorosamente, a inércia circular implica a não-conservação da velocidade linear em alguns dos movimentos numa Terra móvel discutidos por Galileu no Diálogo de 1632. Por exemplo, no caso das quedas verticais - de que trata Feyerabend, como vimos, em seu enunciado do "princípio da inércia circular" - deveria ocorrer uma diminuição da velocidade tangencial da pedra, conforme ela realiza seu movimento descendente.

Vejamos como isso se explica. Consideremos arcos concêntricos que são percorridos em tempos iguais e com velocidades angulares iguais; a figura abaixo mostra que, nesses tempos iguais, os arcos percorridos a são menores conforme são mais próximos do centro comum (de acordo com a fórmula $a=\Delta \alpha . r$, onde $\Delta \alpha$ é o ângulo comum percorrido, em radianos, e r é a distância dos pontos de um arco ao centro comum ou, mais simplesmente, seu raio de revolução), o que leva a uma diminuição similar das velocidades lineares correspondentes.

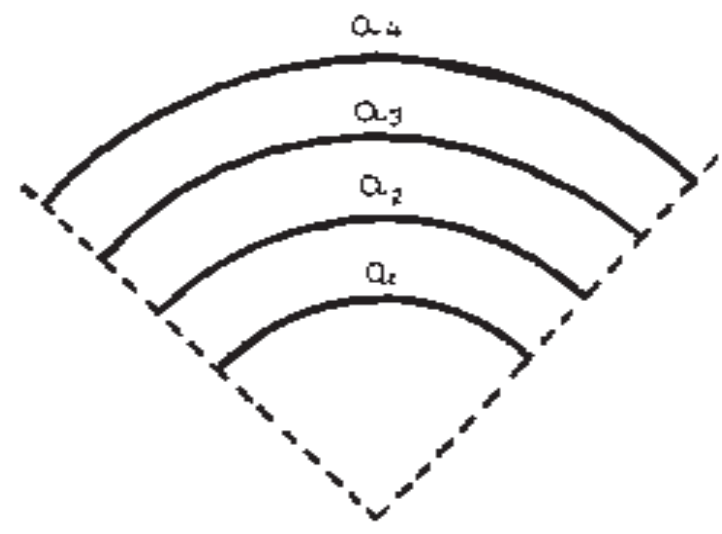

$a_{1}<a_{2}<a_{3}<a_{4}$

para $\Delta \mathrm{t}_{1}=\Delta \mathrm{t}_{2}=\Delta \mathrm{t}_{3}=\Delta \mathrm{t}$

assim: $\mathrm{v}_{1}<\mathrm{v}_{2}<\mathrm{v}_{3}<\mathrm{v}_{4}$

Embora a linguagem empregada nos parágrafos acima tenha elementos estranhos ao século xviı, a propriedade cinemática que descrevem não é anacrônica, na medida em que é inevitável a quem quer que esteja familiarizado, como é o caso de Galileu, com as propriedades elementares das circunferências e dos movimentos circulares uniformes. 
No caso de uma pedra que cai verticalmente numa Terra que gira, com seu movimento entendido como composto por um movimento vertical em direção ao centro terrestre e por outro circular, em torno do centro, este último deve preservar a velocidade angular para que a bala permaneça sempre sobre a mesma vertical, como muito bem destacou Feyerabend em seu enunciado do "princípio da inércia circular" que vimos antes.

E, acontecendo essa preservação da velocidade angular, os arcos que seriam percorridos em tempos iguais diminuiriam com a altura em que a pedra se encontra em cada momento, conforme nos ensinou o esquema da figura que estamos discutindo. Assim, a pedra, conforme se aproxima do centro da Terra, deveria ter velocidade linear horizontal decrescente em cada instante de seu movimento circular (embora o movimento vertical se acelere), para que possa manter-se sempre sobre a boca da peça de artilharia.

Ora, essa característica é incompatível com o pronunciamento de Galileu que se lê no escólio de Iı-23 dos Discorsi, que vamos aqui citar grifando as palavras mais reveladoras da incompatibilidade:

[...] deve-se observar que um grau de velocidade qualquer, uma vez comunicado a um móvel, imprime-se nele de forma indelével por sua própria natureza, desde que não intervenham causas externas de aceleração ou retardamento, o que acontece apenas no plano horizontal (EN, 8, p. 24,3; Galilei, 1988, p. 213).

Pode-se mostrar que a expressão "grau de velocidade" é empregada nos Discorsi em contextos em que as conceituações de velocidade se assemelham a nosso conceito de velocidade (instantânea) linear e não ao de velocidade angular, entre outras razões porque se aplicavam a movimentos retilíneos, em que a velocidade angular - se se insiste em aplicar este conceito - deve ser dita nula. Há, então, uma clara incompatibilidade entre a inércia circular e esta proposta de conservação dos Discorsi, quando se consideram, numa Terra esférica girante, os movimentos de uma pedra cadente (ou de uma bala atirada verticalmente para cima). ${ }^{6}$ E, infelizmente para os defensores da inércia circular, por duas vezes Galileu se dá conta dessa incompatibilidade no próprio Diálogo e, como veremos a seguir, resolutamente opta pela proposta de preservação da velocidade linear que acabamos de ler na citação acima dos Discorsi.

6 Registre-se que a chamada "física clássica", ao considerar movimentos circulares "sem torques externos", recusará tanto a conservação da velocidade angular proposta na inércia circular de Feyerabend como a preservação do grau de velocidade de Galileu, afirmando que tais movimentos circulares conservam o "momento angular", o que implicará que as velocidades lineares v1 e v2 sejam inversamente proporcionais aos raios rı e r2, enquanto as velocidades angulares $\mathrm{w}_{1} \mathrm{e}_{2}$ sejam inversamente proporcionais aos quadrados dos raios $r$ e $r 2$. 
É bem verdade que na passagem do Diálogo conhecida como bizzarria, Galileu explicitamente conceitua a queda de uma pedra como quer a interpretação da inércia circular. Nesse notável trecho, uma queda do alto $C$ de uma torre $C B$ (como mostra a figura) é explicada como resultado da composição do movimento de rotação terrestre, que o cimo da torre e a pedra compartilham pelo círculo CFGHLD, com o movimento vertical desta para o centro $A$ da Terra (o único dos dois movimentos que é visto por um observador no referencial da Terra, junto à torre). O resultado da composição é, segundo Galileu, o movimento circular por CIA.

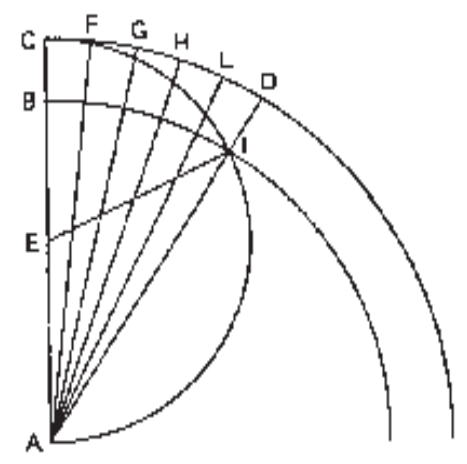

Note-se agora que a figura nos mostra que o movimento resultante tem o dobro da velocidade angular da rotação terrestre (uma vez que CIA tem $180^{\circ}$ enquanto os círculos descritos pelos extremos $\mathrm{Ce} \mathrm{B}$ da torre têm $90^{\circ}$ ), contrariando a proposta de conservação da velocidade angular proposta no enunciado de Feyerabend. Mas é inegável que a bizzarria constitui poderosa arma para os defensores da inércia circular que, por isso mesmo, brandem-na vigorosamente; assim, seria desonesto não adiantar algumas das razões pelas quais tentarei mostrar em próximo artigo que esses golpes não constituem argumento decisivo. São elas, a meu ver:

(a) a incompatibilidade acima denunciada com a conservação da velocidade angular, que é pedra de toque da proposta feyerabendiana de inércia circular;

(b) a também inadequação do enunciado de Dijksterhuis que, ao excluir a gravidade das forças externas, acaba inadvertidamente propondo que a pedra abandonada do alto da torre não cai mas persevera em um movimento circular tendo o centro da Terra como seu centro;

(c) a ausência de uma efetiva demonstração, por parte de Galileu, da solução CIA (que ele apresenta abruptamente), o que no mínimo proíbe, quero crer, dizer ser um "princípio" a inércia circular, na medida em que esta não é utilizada como ferramenta de demonstração na bizzarria; 
(d) o próprio termo, bizzarria, com que Galileu nomeia as reflexões desse trecho;

(e) o fato de ele as chamar de scherzo (brincadeira) numa carta a Carcavy;

(f) a coerência da conceituação da bizzarria com a conservação que declarei ser aquela que pode unificar todos os pronunciamentos de Galileu sobre o tema, a conservação do grau de velocidade - coerência impressionantemente detalhada em "três pequenas meditações" de Salviati no fechamento da bizzaria (cf. EN, 7, p. 192-3; Galilei, 2001, p. 247-8).

\section{A quedA DESDE o ORBE DA LUA}

Uma das instâncias reveladoras da incompatibilidade da inércia circular com a conservação do grau de velocidade ocorre na Segunda Jornada do Diálogo, em uma fala de Salviati, no interior da discussão - nunca citada pelos defensores da inércia circular relativa ao tempo de queda de um corpo abandonado no orbe da Lua. Após Simplício afirmar que se uma bala caísse "por um intervalo tão grande, seria uma coisa admirável que ela possuísse o instinto da natureza de manter-se sempre sobre o mesmo ponto da Terra, sobre o qual ela estava no momento de sua partida, e não ficar para trás por um espaço muito grande", Salviati responde:

O efeito pode ser ou não ser admirável, mas é natural e ordinário, conforme são as coisas precedentes. Pois, se a bala (conforme as suposições que faz o autor) enquanto se mantinha no côncavo da Lua tinha o movimento circular das vinte e quatro horas juntamente com a Terra e com o restante do contido dentro desse côncavo, aquela mesma virtude que a fazia girar antes de descer, continuará a fazê-la girar também na descida; e tantum abest que ela não acompanhe o movimento da Terra, mas deva ficar para trás, ao invés de dever antecipá-lo, sendo que, a o aproximar-se da Terra, o movimento giratório deve ser continuamente feito por círculos menores: de modo que, mantendo-se na bala aquela mesma velocidade que ela tinha no côncavo, deveria antecipar, como afirmei, a rotação da Terra (EN, 7, p. 259-6o; Galilei, 2001, p. 315; grifos meus).

Como se viu, enquanto a bala cai desde o orbe da Lua, ela deve manter sua velocità (linear), de modo que a velocidade angular precisa aumentar, já que há diminuição dos raios das circunferências que a bala atravessa. Assim, é aceitável para Galileu que a velocidade angular não se conserve mas cresça durante uma queda de altura comparável ao raio da Terra; o que lhe é impensável é uma variação da velocidade, coerentemente com a declaração reproduzida mais acima de que é indelével a impressão do grau 
de velocidade inicial na ausência de forças motrizes ou resistivas. Aqui, no caso dessa queda cósmica, esse grau de velocidade é o da rotação inicial no orbe da Lua, de modo que, ao final da queda, o período de giro da bala cadente é significativamente menor que 24 , horas.

Ora, essa declaração é incompatível com a inércia circular conforme proposta por Feyerabend para dar conta da pequena queda do alto de uma torre. A inércia circular funciona no caso da torre porque é desprezível a diminuição dos raios das circunferências que a pedra atravessa e não há conflito entre a conservação da velocidade linear - afirmada por Galileu - e a suposta conservação da velocidade angular - desejada por Feyerabend. Mas, como vimos, quando o conflito se evidencia, Galileu não hesita em tomar o partido da permanência daquela mesma velocidade - linear - que o cadente tinha inicialmente.

\section{A REGUSA DA INÉRGIA GIRGULAR NO TIRO ÀS AVES EM Vôo}

Logo depois de discutir, no Diálogo, como seriam os tiros de artilharia numa Terra que se movesse em rotação em torno de seu eixo, Galileu nos brinda com outra inequívoca recusa da conservação da velocidade angular que Feyerabend explicitou como característica essencial da inércia circular.

Mas num primeiro momento, a inércia circular parece triunfar e, espantosamente, pela boca do próprio Salviati, o porta-voz das concepções de Galileu, que afirma ter ouvido de um "desses atiradores [às aves em vôo] que operam exatamente do mesmo modo que quando atiram na ave parada, ou seja, que ajustam a mira na ave em vôo, e seguem o vôo com o movimento do arcabuz, mantendo sempre a mira sobre a ave até que disparam e, desse modo, as atingem como as que estão paradas [...]" (EN, 7, p. 203-4; Galilei, 2001, p. 259).

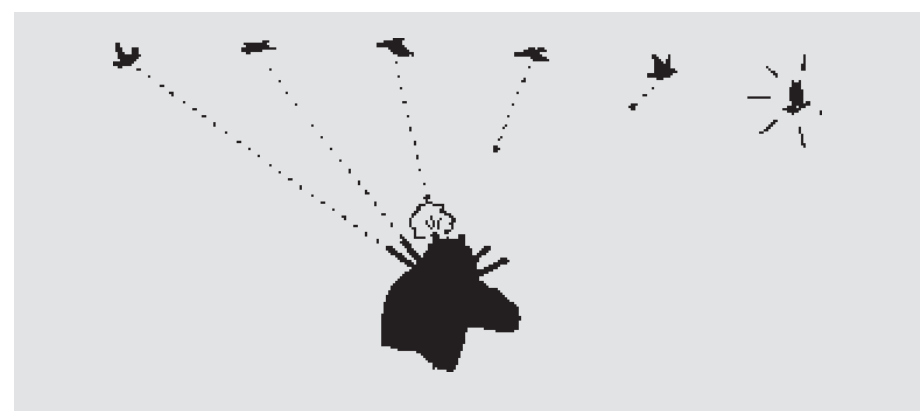


A figura acima (reproduzida de Balibar, 1988, p. 65) ilustra o que Salviati quer dizer. A bala que sai da arma preservaria sua velocidade angular de modo que, mesmo situando-se em circunferências a cada instante progressivamente maiores, permanece sempre na linha que une a arma à ave e acaba por atingi-la. A semelhança com o tiro vertical numa Terra em movimento é evidente e, mais do que isso, Salviati faz questão de, logo a seguir, declarar essa semelhança:

[...] É necessário, portanto, que aquele movimento, ainda que lento, que o arcabuz faz ao deslocar-se, acompanhando com a mira o vôo da ave, seja comunicado também para a bala e que nela se combine com o outro do fogo, de modo que a bala tenha do fogo o movimento em linha reta para o alto, e do cano o movimento inclinado acompanhando o vôo da ave, exatamente como acabamos de dizer a respeito do tiro de artilharia; onde a bala obtém do fogo o movimento para cima em direção ao vértice, e do movimento da Terra o inclinar-se para o oriente e de ambos fazer um composto que siga o curso da Terra e que, para quem olha, apareça dirigir-se diretamente para cima, retornando depois pela mesma linha para baixo (EN, 7, p. 204; Galilei, 2001, p. 259).

O "vértice" é, no raciocínio de Salviati, um ponto geométrico que se constitui numa espécie de alvo móvel como a ave que voa, alvo a que o canhão fixo sobre a superfície terrestre está permanentemente mirando, tal como sempre mira a ave o arcabuz do caçador. Salviati prossegue, utilizando esse elegante raciocínio para rebater outro argumento contrário às teses copernicanas, o de que tiros para o sul e para o norte "resultariam desviados para ocidente" devido à rotação da Terra.

Note-se que aqui se tem um grupo de aplicações de uma inércia circular mais radical do que a de Feyerabend e Dijksterhuis, pois aparentemente qualquer movimento circular é conservado, e exatamente na característica apontada por Feyerabend, ou seja, na velocidade angular. Porém, infelizmente para quem pretende defender uma versão forte da inércia circular, o fluxo exuberante de considerações de Salviati é abruptamente interrompido por Sagredo, o personagem que representa no Diálogo e nos Discorsi o homem culto e aberto às novas conceituações:

Parai um pouco, por favor, sr. Salviati, para que eu proponha outra idéia que me ocorreu a respeito desses caçadores de aves voadoras: cujo modo de operar acredito que seja como dissestes, e acredito igualmente que se siga o efeito de ferir a ave; mas não me parece que tal operação seja totalmente conforme a essa dos tiros de artilharia, os quais devem atingir tanto no movimento da peça e do alvo, quanto no repouso comum a ambos: e as diferenças me parecem ser estas. 
No tiro de artilharia, tanto a artilharia como o alvo movem-se com a mesma velocidade, sendo ambos levados pelo movimento do globo terrestre; e ainda que às vezes a peça seja colocada mais para o pólo que o alvo e, conseqüentemente, o seu movimento seja um tanto mais lento, por ser feito num círculo menor, tal diferença é insensível, devido à pouca distância da peça ao alvo: mas no tiro do caçador, o movimento do arcabuz, com o qual segue a ave, é lentíssimo em comparação ao vôo daquela; do que me parece seguir-se que aquele pequeno movimento que é conferido pelo cano à bala que está dentro dele, não possa, uma vez que ela tenha saído, multiplicar-se pelo ar até a velocidade do vôo da ave, de modo que esta bala se mantenha sempre dirigida para ela; ao contrário, parece que a ave deva antecipá-la e deixá-la para trás. Acrescente-se que nesse ato o ar pelo qual deve passar a bala não se supõe ter o movimento da ave; mas, no caso da artilharia, a bala e o alvo e o ar intermediário participam igualmente do movimento universal diurno. De modo que acredito que são razões do tiro certeiro do caçador, além do acompanhar o vôo com o movimento do cano, o antecipá-lo um pouco, mantendo a mira à sua frente e, além disso, o atirar (como acredito) não com uma só bala, mas com um bom número de pequenas balas, as quais, espalhandose pelo ar, ocupam um espaço muito grande e, além disso, a extraordinária velocidade com a qual se dirigem para a ave ao sair do cano (EN, 7, p. 205; Galilei, 2001, p. 260; grifos meus).

Ao que um Salviati enternecido e grato pelo esclarecimento exclama, encerrando a discussão do tema:

Eis aí em quanto o vôo da inteligência do sr. Sagredo antecipa e supera a lentidão do meu, o qual possivelmente teria advertido estas diferenças, mas não sem uma demorada aplicação da mente (EN, 7, p. 205; Galilei, 2001, p. 260).

Voltando à fala de Sagredo: as palavras que lá ressaltamos em itálico mostram uma negação clara da conservação da velocidade angular e do conseqüente aumento da velocidade linear que Salviati repetidas vezes propôs. Como explicou Sagredo, só enquanto a diferença entre os círculos é insensível, como no caso dos tiros sobre uma Terra móvel, os graus de velocidade do projétil e do alvo são praticamente iguais e este último pode ser atingido.

Com a recusa de Sagredo, apoiada pelo elogio de Salviati, de que um grau de velocidade possa multiplicar-se como por geração espontânea de novos graus de velocidade, ${ }^{7}$ evidencia-se que a conservação do grau de velocidade é a característica mais fundamental do que se pode chamar "lei de inércia de Galileu", e revela-se insusten- 
tável a presunção dos defensores da inércia circular de que sua interpretação descreva perfeitamente o conceito galileano de movimento inercial.

Assim, compreende-se porque Dijksterhuis, Feyerabend e outros não citam as considerações acima de Salviati, apesar delas estarem em consonância com a sua interpretação. E a razão é simples: se as citassem, aqueles analistas não poderiam omitir a fala de Sagredo que se interpõe à conclusão de Salviati, e seriam eles os próprios responsáveis por fazer ecoar o tiro mortal que ouvimos Sagredo desferir na inércia circular.

\section{Inércia em GaLileu: Nem retilínea, Nem Girgular}

Em alguns momentos da leitura das discussões acima descritas de Sagredo e Salviati, é possível que um leitor instruído nas leis da física clássica se pergunte se eles não oferecem evidências de que Galileu tem a conceituação do moderno princípio de inércia, embora não o enuncie como tal.

É grande a tentação de conceder ao nosso pisano essa precedência (o próprio Isaac Newton o fez, como se sabe). Mas deve-se resistir a essa concessão em respeito, justiça seja feita, a considerações dos defensores da inércia circular sobre várias passagens do Diálogo não comentadas no presente trabalho mas, como já se reconheceu, tão sugestivas quanto as que aqui se apresentaram, passagens em que se lêem afirmações sobre a tendência de conservação dos movimentos circulares. Assim, uma descrição das concepções inerciais de Galileu deve, ao mesmo tempo, dar conta dos trechos citados no presente trabalho e daqueles em que se apóiam Feyerabend, Dijksterhuis e outros que defendem a inércia circular.

A proposta que aqui se apresenta é a de tomar como conceito galileano de conservação de movimento o trecho de III-23 citado acima, no qual - como se pode notar na reapresentação que dele fazemos abaixo - não há referências às trajetórias ou a quaisquer outras características geométricas dos movimentos:

[...] deve-se observar que um grau de velocidade qualquer, uma vez comunicado a um móvel, imprime-se nele de forma indelével por sua própria natureza, desde que não intervenham causas externas de aceleração ou retardamento; [...] (EN, 8, p. 243; Galilei, 1988, p. 213).

7 Incompatibilidade similar existe para o caso da pedra que cai do alto da torre mas, como mostra Koyré (1955, p. 358-6o), nem Galileu nem Fermat nem Mersenne a denunciaram; foi Borelli o primeiro a afirmar que, durante aquela queda, os "espaços iguais que são atravessados pelo impetus, que persevera na mesma força, compreenderão ângulos centrais sucessivamente maiores" (Borelli apud Koyré, 1955, p. 359), o que implica que a pedra acaba por superar em rapidez a superfície da Terra e cai a leste do pé da torre (cf. Koyré, 1955, p. 360). 
A título de conclusão, propõe-se que este é o enunciado que melhor caracteriza a lei da inércia ${ }^{\mathbf{8}}$ de Galileu; pois em todos os momentos em que considerações sobre movimentos inerciais se impõem nos escritos de Galileu, sua decidida e firme escolha é pela afirmação da preservação do grau de velocidade, seja qual for o movimento que estiver sendo considerado.

Isso se mostrou para os trechos destacados no presente artigo e também pode ser mostrado valer para os trechos brandidos pelos adeptos da inércia circular: é a limitação de escopo e de extensão deste artigo que impede que esse trabalho seja feito aqui; o que não impede o leitor de conceder provisoriamente a legitimidade da proposta. Com o entendimento de que em Galileu há uma lei de conservação do grau de velocidade dissolve-se o conflito interpretativo inércia circular versus inércia retilínea e se podem ler de modo unificado as jornadas dos Discorsi em que Galileu nos expõe sua ciência do movimento e as etapas de batalha da Segunda Jornada do Diálogo.

Esperamos que o leitor concorde que não é pouca coisa o que se obtém com essa lei de conservação do grau de velocidade que, embora diferente da lei de inércia newtoniana, é também conceitualmente rica e, de acordo com a opinião do próprio Newton, sua legítima antecessora. E, como se argumentará a seguir, Galileu não precisa de outra coisa.

Sabemos que Newton precisará de uma lei de inércia retilínea porque não encontrará modo melhor de explicar a intrigante trajetória elíptica dos planetas descoberta por Kepler. Aí então será preciso ver os movimentos curvilíneos como retilíneos a cada instante, desviados nesses instantes por uma força central. Mas a tarefa cosmológica de Galileu é outra: é a de convencer seus contemporâneos de que podem girar em círculos com os outros planetas pelos céus. Não é preciso explicar os círculos e não é preciso, assim, reduzir o movimento circular ao movimento retilíneo. Não é necessário um princípio de inércia retilínea, basta argumentar com um conceito mais geral de conservação do grau de velocidade de um móvel.

E na ciência do movimento que será exposta nos Discorsi, anos depois da publicação do Diálogo, Galileu não formula o princípio de inércia como o conhecemos porque, uma vez mais, não precisa dele. A ciência do movimento que apresenta naquele livro se apóia em outro princípio, o da igualdade do grau final de velocidade de quedas por planos inclinados de igual altura, perfeitamente suficiente para sustentar seus teoremas e problemas, princípio que fornece, entre outros resultados, um teorema da inércia que é um importante instrumento de demonstração na subseqüente teoria dos projéteis.

8 Cf. Vasconcelos $(1993 ; 2001)$ para o argumento de que essa lei não deve ser entendida como um princípio, na medida em que não é usada como instrumento de demonstração nos Discorsi, a não ser na "segunda via" de demonstração do teorema da inércia no escólio ("escólio", ou seja "explicação") de Iıı-23. 
Assim, no Diálogo e nos Discorsi não está um rascunho da física newtoniana, um rascunho ao qual faltaria o princípio de inércia retilíneo, mas uma ciência original, com outros objetivos e conquistas, uma ciência que não precisa de um princípio de inércia para ser considerada completa e admirável por qualquer físico moderno. Desse modo, os esforços de Galileu apontam para uma direção diferente das motivações newtonianas. Apesar disso, esperamos que este trabalho também contribua para uma reflexão sobre o sentido da afirmação, na qual não deixam de ter razão, daqueles que, como Newton, atribuem ao pisano a honrosa paternidade do moderno princípio de inércia.

\author{
Júlio Ceelso Ribeiro de Vascongelos \\ Professor Adjunto do Departamento de Filosofia \\ da Universidade Estadual de Feira de Santana; \\ da Universidade Estadual de Feira de Santana e \\ da Universidade Federal da Bahia. \\ juliovasconcelos@uol.com.br
} Docente do Mestrado em Ensino, Filosofia e História das Ciências

\begin{abstract}
According to the scholars who propound 'circular inertia' as one of the main aspects of Galileo's conceptual frame, the Italian pioneer of modern physics believed that only circular motions around the center of a cosmic body like the Earth could persist without action of a force. This widely accepted interpretation is based upon excerpts from the two Galileo's masterpieces, the 1632 Dialogue and the 1638 Discorsi. Those scholars, nevertheless, do not take into consideration other passages from those books in which Galileo's words do not fit their interpretation. These passages will be brought to light in order to reject the 'circular inertia' interpretation and in order to support the viewpoint that Galileo's concept of inertia does not take into account the path of a motion, but deals solely with the "degree of speed indelibly impressed" on a moving body.
\end{abstract}

KEYWORDS $・$ Inertia. Circular inertia. Conservation of motion. Mechanics. Galileo.

\title{
REFERÊNGIAS BIBLIOGRÁFIGAS
}

Balibar, F. Einstein: uma leitura de Galileu e Newton (espaço e relatividade). Lisboa: Edições 7o, 1988. Dijksterhuis, E. The mechanization of the world picture. Princeton: Princeton University Press, 1986. Favaro, A. (Ed.). Edizione nazionale delle opere di Galileo Galilei. Firenze: Barbèra Editore, 1929-1939. 20 v. (EN)

Feyerabend, P. Contra o método. Rio de Janeiro: Francisco Alves, 1977. 
Galilei, G. Dialogo sopra i due massimi sistemi del mondo. In: Favaro, A. (Ed.). Edizione nazionale delle opere di Galileo Galilei. Firenze: Barbèra Editore, 1933. v. 7.

. Discorsi e dimostrazioni matematiche intorno a due nuove scienze. In: Favaro, A. (Ed.). Edizione nazionale delle opere di Galileo Galilei. Firenze: Barbèra Editore, 1933. v. 8.

. Duas novas ciências. Trad. de L. Mariconda \& P. R. Mariconda. São Paulo: Nova Stella, 1988.

. Diálogo sobre os dois máximos sistemas do mundo ptolomaico e copernicano. Trad., introd. e notas de P. R. Mariconda. São Paulo: Discurso Editorial/Fapesp, 2001.

KoYrÉ, A. A documentary history of the problem of fall from Kepler to Newton. Transactions of the American Philosophical Society, 45, p. 329-95, 1955.

Vasconcelos, J. R. de. Um teorema da inércia e o conceito de velocidade dos Discorsi de Galileu. Cadernos de História e Filosofia da Ciência, série 3, 3, 1/2, p. 67-83, 1993.

"Inércia circular" nos Discorsi de Galileu: interpretação ou erro de tradução? Cadernos de História e Filosofia da Ciência, série 3, 11, 1, p. 81-94, 2001. 